\title{
Data exchange facilitated
}

To the Editor - A recent Commentary ${ }^{1}$ in Nature Geoscience points out a gap between the principles and actions of data sharing in geoscience, and urges professional support for the archiving of data during its creation. We agree with these points, but we would like to add that attention should also be paid to the interoperability of data. Data should be discoverable, accessible, decodable, understandable and usable, and data sharing should be legal and ethical for all participants ${ }^{2}$. Without interoperability in this sense, local geoscience data archives will run the risk of becoming separate islands in a data deluge ${ }^{3}$.

To tackle issues in Earth and environmental sciences - such as climate change, earthquakes, flooding and pollution - on regional and global levels, geoscience data are often collected and integrated from diverse sources. Interoperability of these data is essential. It is now possible to download thematic spatial data from any number of websites in seconds. However, it can be difficult to understand these data on schematic and semantic levels and align them with each other, or even to use them appropriately. Rich data assets - such as those existing in geological surveys all over the world - are not easy to understand or use for those outside an institution or nation ${ }^{4}$.

To tackle these difficulties, two projects, OneGeology 5 and OneGeology-Europe ${ }^{4}$, provide examples of schematic and semantic interoperability, and suggest a strategy of collaborative modelling and encoding to enable interoperability of geoscience data on the Internet ${ }^{6}$. A common data model, GeoSciML, is used to mediate distributed geological maps and information made available from participating nations.

Various data users need to be able to use diverse languages and different definitions in local geoscience data archives. Interoperability does not mean that all data should be mediated or standardized. However, it is important that data archives are accompanied by detailed documentation, clarifying data provenance, data model, vocabularies used, and so on. The documentation will facilitate interoperability among heterogeneous data sources.

\section{References}

1. Fleischer, D. \& Jannaschk, K. Nature Geosci. 4, 575-576 (2011).

2. High Level Expert Group on Scientific Data Riding the Wave: How Europe can Gain from the Rising Tide of Scientific Data (European Union, 2010). Available via: http://cordis.europa.eu/fp7/ict/einfrastructure/docs/hlg-sdi-report.pdf
3. Ma, X. et al. Comput. Geosci. 36, 1512-1522 (2010).

4. Jackson, I. (ed.) One Europe One Geology: Applying Geoscience for Society (OneGeology-Europe Consortium, 2010). Available via: http://www.onegeology.org/docs/Oneeurope_Onegeology eBook/flash.html

5. Charles, K. Nature 454, 675 (2008).

6. Asch, K. Episodes 33, 280 (2010).

Xiaogang $\mathrm{Ma}^{{ }^{*}}$, Kristine Asch ${ }^{2}$, John L. Laxton ${ }^{3}$, Stephen M. Richard ${ }^{4}$, Carlos G. Asato ${ }^{5}$, Emmanuel John M. Carranza', Freek D. van der Meer $^{1}$, Chonglong $\mathrm{Wu}^{6}$, Guillaume Duclaux ${ }^{7}$ and Koji Wakita ${ }^{8}$

${ }^{1}$ Faculty of Geo-Information Science and Earth Observation (ITC), University of Twente, PO Box 217, 7500 AE Enschede, The Netherlands, ${ }^{2}$ Federal Institute for Geoscience and Natural Resources (BGR), Stilleweg 2, 30655 Hannover, Germany, ${ }^{3}$ British Geological Survey, Murchison House, West Main Road, Edinburgh EH9 3LA, UK, ${ }^{4}$ Arizona Geological Survey, 416 W. Congress St, Suite 100, Tucson, Arizona 85701, USA, ${ }^{5}$ Geological and Mining Survey of Argentina, Av. Julio A. Roca 651 - p 8 of 1, 1322 Buenos Aires, Argentina, ${ }^{6}$ School of Computer

$\neg$ Science, China University of Geosciences, Wuhan 430074, Hubei, China, ${ }^{7}$ CSIRO, Earth Science and Resource Engineering, PO Box 1130, Bentley, Western Australia 6102, Australia, ${ }^{8} \mathrm{Geological}$ Survey of Japan, AIST Tsukuba Central 7, Tsukuba, 305-8567, Japan. *e-mail: xiaogang@itc.nl 